\title{
Presence Of Informational Attributes In MIS Reports
}

P.K. Malik, G.N.K. (PG) College, India

Ranjana Malik, G.N.G. (PG) College, India

\begin{abstract}
MIS is an organizational information system which supports not only operations but also the management processes by providing the 'right information' to the 'right people' at the 'right time' and at the 'right cost'. The information is said to be right when it possesses all the attributes like timeliness, accuracy and reliability, adequacy, consistency and uniformity, brevity, need based, economy, predictive ability, etc. Right people means 'one information not to all the decision makers and all the information not to one decision maker'. Right time and right cost do not need any explanation. When these four rights are right, MIS is bound to be right and effective in discharging its role.
\end{abstract}

Keywords: Management Information System (MIS); Information; Informational Attributes; System; Corporate Reports

\section{INTRODUCTION}

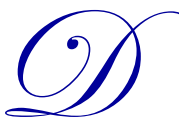

ue to the increasing size and complexities of business organizations the old techniques of management such as intuition, rule of thumb, personal prestige, etc. are no longer considered reliable in the decision making processes and an executive finds it difficult to retrieve relevant information quickly within the response time available and to hold back irrelevant information. This has led to the development of a new resource of great importance described by words like computer, data, information, processing and system combined in to expressions like information system, data processing system, information decision system, computer technology, decision support system (D.S. S.) and information resource management (I.R.M.).

Our troubles begin right away when we address ourselves to the question of what is an "MIS'. There are numerous definitions given by different contributors to the literature, but lacking consensus, as to what really constitutes an MIS. Consequently, nearly every paper written on the subject begins with the author's favorite definition based on his experience.

\section{MIS DEFINED}

A comprehensive definition of MIS which has management view point rather than equipment and tools used in processing is given by R.G Murdick and J.E Ross ${ }^{1}$.

"Management for purposes of MIS consists of activities carried out by managers. They plan, organize and control the major activities of the organization and initiate action. Because decision making is a major requirement for each of the managerial functions, the MIS becomes a facilitating system for developing decisions in planning, organizing, controlling and initiating. This gives the purpose of MIS.

Information is definitely different from data and this distinction is very important. Data are facts and figures that are not currently being used in a decision process. Files, records and reports not under consideration are

\footnotetext{
${ }^{1}$ Murdick, R.G. and Ross, J.E. : "Information System for Modern Management', 2nd ed., Prentice Hall of India Pvt. Ltd., Delhi, pp 5-6

(C) 2013 The Clute Institute http://www.cluteinstitute.com/ 
examples. By contrast information consists of classified and interpreted data that are being used for decision making.

A system is a set of two or more elements such as people, things and concepts which are joined together to attain a common objective. A properly functioning system is characterised by its synergy. That is all sub- systems or elements work more efficiently together than if they were operating independently. MIS is the means for connecting the managed operating systems by exchange of information".

C. Lucas, $\mathrm{Jr}^{2}$. has defined MIS as "An information system is set of organized procedures which when executed provides information to support decision- making. Information is tangible or intangible entity which saves to reduce uncertainty about some future state or event."

To Paul Siegel ${ }^{3}$, "An MIS is not a sophisticated computer system, a communication network, a generalized data base management system, an accounting system. The MIS is a philosophy, an approach, a point of view, a way of seeing the organization as a whole. It is at the core of a hierarchy of systems."

MIS, in nutshell, is an organizational information system which supports not only operations but also the management processes by providing the 'right information' to the 'right people' at the 'right time' and at the 'right cost'. The information is said to be right when it possesses all the attributes in it. Right people means 'one information not to all the decision makers and all the information not to one decision maker'. Right time and right cost do not need any explanation.

\section{NEED OF INFORMATION:}

Information system produces information to satisfy the needs of both the management and operational subsystems as well as the needs of parties external to the organization. This information reflects the internal activities of the organization, competitive actions, environmental and sociological interests and political and financial trends. It must represent what has happened?, what is happening? and perhaps most important of all, what will happen? This information requirement exists with equal significance in private industry, educational institutions, government agencies, the military, hospitals and various other organizations.

The information to be useful must have certain features or attributes in it. The success of MIS greatly depends upon the quality of information generated by MIS. These attributes are accuracy, relevance, timeliness, completeness, usefulness, reliability, validity, consistency, need based, adequacy, flexibility, economy and based on the principle of exceptional reporting and must have predictive ability.

\section{METHODOLOGY}

To carry out the present study of MIS obtaining at management control levels and the extent of presence of informational attributes, ten companies in all selecting five from each of the two, public and private sectors, were included in the sample. The five public sector undertakings (PSUs) selected were National Mineral Development Corporation (NMDC) Ltd., Hyderabad; Project Equipments Corporation of India (PEC) Ltd., New Delhi; Coal India Ltd. (CIL) Dhanbad, Bihar; Steel Authority of India Ltd. (SAIL), Bokaro and Bharat Heavy Electrical Ltd., (BHEL), Haridwar. Similarly five private sector enterprises (PSEs) were Ballarpur Industries Ltd. (BILT) - Shree Gopal Division, Yamuna Nagar; Bharat Starch Chemicals Ltd. (BSCL), New Delhi; Yamuna Syndicate Ltd. (YSL), Yamuna Nagar; Larsen and Toubro (L\&T), Mumbai and Escorts Ltd., Faridabad.

The sample comprises only the large industrial undertakings having computerized MIS. This being the major consideration, the selection was made irrespective of the nature of business, amount of capital employed, location of plant, etc. The primary data were collected with help of structured questionnaire. 25 executives at

\footnotetext{
${ }^{2}$ Lucas] Henry C. (Jr.) : 'Information System: Concepts for Management, $2^{\text {nd }}$ Ed., New York, McGraw Hill Book Co., 1982, p.3.

3 Siegel, Paul : 'Strategic Planning of Management Information System,' Mason and Lips Comp. Publishers, New York, 1975, p.3. 
management control levels were approached in each of the sectors. The respondents of both the sectors were asked to explain the extent of presence of informational attributes in the reports supplied by their respective MIS. Their responses have been summarized in a table. The analysis of various attributes shows:

(i) Timeliness - Timeliness means that information must reach the recipients within the prescribed time-frame. The value of information is eroded if its dissemination is delayed by any fraction of time period. Many authors have advocated the importance of timeliness. Chatterjee, B. $\mathrm{K}^{4}$. has gone one step further and said that "information delayed is information denied."

Operational level managers lay greater emphasis on timeliness attribute of information as these managers have to act immediately. The strategic level managers' emphasis on this attribute is low in comparison to operational level managers as long term planning does not get affected adversely if some reports are a bit late. Management control level managers are placed in between the two levels as far as timeliness of information is concerned.

Regarding the generation of reports , 44 percent of the PSU respondents felt that it was 'always' in time, 52 percent said 'occasionally' and 4 percent didn't reply, while in case of PSEs, it was 40 percent, 36 percent and 20 percent respectively in addition to 4 percent who said reports generated were 'never' in time

For the reports received by MCL managers, 40 percent of PSU respondents informed that they 'always' received the reports in time, 40 percent 'occasionally' and 20 percent did not reply, while for the same in PSEs, it was 12 percent, 52 percent, and 36 percent respectively.

It is evident from the above analysis that under both the sectors, a large percentage of MCL managers are not receiving the reports in time, causing the delay in generation of reports by them. Thus, MIS in both sectors has not come up as very efficient in so far as the timeliness of reporting is concerned.

(ii) Reliability and Accuracy - Accuracy is another key attribute of information. As per Urch, John G. and Grudnitski, Gray ${ }^{5}$, accuracy means more than 'one plus one equals two,' it means that information is free from mistakes and errors and accurately and reliably reflects the meaning of data on which it is based. It conveys an accurate picture to the recipient and is free from bias. Advani, H.C. ${ }^{6}$ has advocated the importance of accuracy by stating that wrong information given to management would result in wrong decisions. However, at the same time, he has cautioned that accuracy should be within limits or as desired and should not be achieved by sacrificing promptitude.

Operational level managers cannot afford any amount of inaccurate information. Being on the lowest level of management hierarchy of an organization, they require exact information. Strategic level managers, however, have a choice of information and may cross-check the accuracy of information from other sources as well. Their decision would not be adversely affected if some inaccuracy of information creeps in. Management control level managers stand in between these two extremes, they too require relatively accurate information as they have to convince the two extreme level managers.

For the reports generated, 52 percent of the PSU respondents viewed that the accuracy and reliability in the reports were 'always' there 20 percent said these were 'occasionally' there and 28 percent did not reply, while in case of PSEs, the similar responses were received from 40 percent, 20 percent and 32 percent of the respondents respectively. Those who expressed that accuracy and reliability were 'never' their constituted only 8 percent.

For the reports received, 48 Percent of PSU respondents observed that accuracy and reliability were 'always' there, 16 percent said 'occasionally' and 36 percent did not reply, while the similar responses in case of PSEs being by 32 percent, 32 percent and 36 percent of the respondents respectively.

\footnotetext{
${ }^{4}$ Chatterjee, B.K. : 'MIS : A Conceptual Framework;, Management Accountant; 9(8), August 1974, pp 585-587.

${ }^{5}$ Urch, John G. \& Grudnitski, Gray; 'Information Systems; Theory and practice, John Wiley \& Sons, Inc., Singapore, Fourth edition, 1986.

${ }^{6}$ Advani, H.C.; 'MIS', Management Accountant, 10 (5), May 1975 pp 369 - 70
}

(C) 2013 The Clute Institute http://www.cluteinstitute.com/ 
Table 1

Presence of Informational Attributes in Reports Generated and Received

\begin{tabular}{|c|c|c|c|c|c|c|c|c|}
\hline \multicolumn{9}{|c|}{ Public Sector Undertakings } \\
\hline \multirow{3}{*}{$\begin{array}{l}\text { Whether reports } \\
\text { Generated and } \\
\text { received are }\end{array}$} & \multirow{2}{*}{\multicolumn{2}{|c|}{ Always }} & \multirow{2}{*}{\multicolumn{2}{|c|}{ Occasionally }} & \multirow{2}{*}{\multicolumn{2}{|c|}{ Never }} & \multirow{2}{*}{\multicolumn{2}{|c|}{ No response }} \\
\hline & & & & & & & & \\
\hline & $\mathrm{G}$ & $\mathrm{R}$ & $\mathrm{G}$ & $\mathrm{R}$ & G & $\mathrm{R}$ & $\mathrm{G}$ & $\mathrm{R}$ \\
\hline In time & $11(44)$ & $10(40)$ & $13(52)$ & $10(40)$ & - & - & $1(4)$ & $5(20)$ \\
\hline $\begin{array}{l}\text { Reliable and } \\
\text { Accurate }\end{array}$ & $13(52)$ & $12(48)$ & $5(20)$ & $4(16)$ & - & - & $7(28)$ & $9(36)$ \\
\hline Consistent & $11(44)$ & $9(36)$ & $10(40)$ & $9(36)$ & - & - & $4(16)$ & $7(28)$ \\
\hline Brief & $12(48)$ & $9(36)$ & $8(32)$ & $8(32)$ & - & - & $5(20)$ & $8(32)$ \\
\hline Need Based & $13(52)$ & $12(48)$ & $9(36)$ & $8(32)$ & - & - & $3(12)$ & $5(20)$ \\
\hline Relevant & $11(44)$ & $10(40)$ & $7(28)$ & $5(20)$ & - & - & $7(28)$ & $10(40)$ \\
\hline Adequate & $11(44)$ & $10(40)$ & $7(28)$ & $5(20)$ & - & - & $7(28)$ & $10(40)$ \\
\hline Flexible & $7(28)$ & $6(24)$ & $10(40)$ & $9(36)$ & $1(4)$ & $1(4)$ & $7(28)$ & $9(36)$ \\
\hline Economical & $11(44)$ & $7(28)$ & $3(12)$ & $4(16)$ & - & - & $11(44)$ & $14(56)$ \\
\hline Factual & $7(28)$ & $7(28)$ & $8(32)$ & $7(28)$ & - & - & $10(40)$ & $11(44)$ \\
\hline Exception based & $4(16)$ & $4(16)$ & $5(20)$ & $4(16)$ & $5(20)$ & $5(20)$ & $11(44)$ & $12(48)$ \\
\hline
\end{tabular}

$\mathrm{G}=$ Generated, $\mathrm{R}=$ Received, Figures = given in parenthesis represent percentages. Source $:$ Field Survey

Table 2

Presence of Informational Attributes in Reports Generated and Received

\begin{tabular}{|c|c|c|c|c|c|c|c|c|}
\hline & & & Priv & ector En & prise & & & \\
\hline Whether reports & & & & & & & & \\
\hline Generated and & Alw & & Occa & ally & $\mathrm{Ne}$ & & No res & \\
\hline received are & $\mathrm{G}$ & $\mathrm{R}$ & $\mathrm{G}$ & $\mathrm{R}$ & $\mathrm{G}$ & $\mathrm{R}$ & $\mathrm{G}$ & $\mathrm{R}$ \\
\hline In time & $10(40)$ & $3(12)$ & $9(36)$ & $13(52)$ & $1(4)$ & - & $5(20)$ & $9(36)$ \\
\hline $\begin{array}{l}\text { Reliable and } \\
\text { Accurate }\end{array}$ & $10(40)$ & $8(32)$ & $5(20)$ & $8(32)$ & $2(8)$ & - & $8(32)$ & $9(36)$ \\
\hline Consistent & $9(36)$ & $7(28)$ & $6(24)$ & $6(24)$ & $1(4)$ & $1(4)$ & $9(36)$ & $11(44)$ \\
\hline Brief & $8(32)$ & $6(24)$ & $9(36)$ & $8(32)$ & $1(4)$ & $1(4)$ & $7(28)$ & $10(40)$ \\
\hline Need Based & $10(40)$ & $7(28)$ & $6(24)$ & $7(28)$ & $1(4)$ & - & $8(32)$ & 11(44) \\
\hline Relevant & $13(52)$ & $9(36)$ & $4(16)$ & $4(16)$ & $1(4)$ & $1(4)$ & $7(28)$ & 11(44) \\
\hline Adequate & $9(36)$ & $7(28)$ & $6(24)$ & $8(32)$ & $1(4)$ & - & $9(36)$ & $10(40)$ \\
\hline Flexible & $6(24)$ & $4(16)$ & $8(32)$ & $7(28)$ & $2(8)$ & $2(8)$ & $9(36)$ & $12(48)$ \\
\hline Economical & $6(24)$ & $6(24)$ & $6(24)$ & $5(20)$ & $1(4)$ & $1(4)$ & $12(48)$ & $13(52)$ \\
\hline Factual & $8(32)$ & $7(28)$ & $7(28)$ & $6(24)$ & - & - & $10(40)$ & $12(48)$ \\
\hline Exception based & $6(24)$ & $5(20)$ & $5(20)$ & $5(20)$ & $2(8)$ & $2(8)$ & $12(48)$ & $13(52)$ \\
\hline
\end{tabular}

$\mathrm{G}=$ Generated, $\mathrm{R}=$ Received, Figures = given in parenthesis represent percentages. Source : Field Survey

It seems that public sector is ahead of private sector in the matter of generating and receiving the reliable and accurate reports. This attribute in MIS reports is present in a greater measure than the timeliness.

(iii) Consistency and Uniformity - The information provided by MIS of an organization should be consistent and uniform. The uniformity and consistency can be ensured by using the prescribed formats and it will also help in checking the duplication. Inconsistent reports reduce the effectiveness of MIS and lead to wastage of time and causes confusion in the mind of manager. It hampers the effective decision-making. The managers at all levels should be provided with consistent and uniform reports.

That the consistency in reports generation was maintained 'always' and 'occasionally' was expressed by 44 percent and 40 percent of PSU respondents, while the similar views were expressed by 36 percent and 24 percent of PSE respondents. In terms of the response generated from the respondents, the consistency with respect to received reports is not much different from that of the reports generated. Moreover, the consistency in reporting has been experienced more in public sector than the private sector.

(iv) Brevity - Nature of details to be provided or the volume of information is also a key-attribute of information. The reports which are generated by MIS of an organization should be balanced in volume of the 
information. Whereas inadequate information as well as more than adequate information may be worse than no information.

Strategic level managers require summary reports but important details should not be curtailed to maintain the brevity. Operational level managers may take wrong decisions if they are given over loaded information as it would become difficult for them to extract the useful information out of the voluminous data and thus a state of confusion will prevail. However, the management control level managers would prefer more information than operational level managers.

To be effective, MIS should produce the brief reports but not by ignoring the relevant and important aspects. How far brevity in reporting is ensured by MIS is indicated by the percentage of responses classified across always, occasionally and never. The respective percentage with respect to reports generated came at 48 percent, 32 percent and 20 percent while in case of PSEs, these worked out to be 32 percent, 36 percent and 28 percent respectively. It was only 4 percent of PSEs respondents who disclosed that brevity was 'never' followed.

For the reports received by MCL manager, 36 percent of PSU respondents felt that brevity was 'always' there, 32 percent said 'occasionally' and 32 percent did not reply, the respective percentages in case of PSEs being 24, 32 and 40. And, remaining 4 percent again informed that brevity was 'never' maintained.

It is obvious from the above examination that MCL managers under both sectors feel that the reports generated by them are more brief than the reports received by them. The public sector has maintained more brevity than the private sector.

(v) Need based - A report is said to be of good quality if it does not require further analysis by the recipient for his decision making. On the other hand, a poor quality report which is not need based require further analysis or processing of its contents. Reports should be such that manager is able to extract the required information without any processing of the data contained in the reports.

Operational level managers must get the need based reports as they have to act spontaneously and no time is left with them for further analysis of reports. Strategic level managers have the time to make further analysis of the information and then it can be said that they may afford, to some extent, the reports which are not need based. Operational level managers have a priority for need based reports while strategic level managers may like to analyse further the reports received.

MIS cannot be effective if it is producing the reports which are not need-based. The survey data reveals that the reports generated were 'always' and 'occasionally' need - based with respect to 52 percent and 36 percent of the cases in PSUs, and 40 percent and 24 percent in case of PSEs. Except 4 percent of the PSE respondents holding the reports were 'never' need based, the remaining maintained a silence on the issue.

For the reports received 48 percent of PSU respondents viewed the reports as 'always' need based, 32 percent 'occasionally' and 20 percent did not reply, while for the same in PSEs, it was 28 percent, 28 percent and 44 percent respectively.

It is obvious from this analysis that MIS in public sector produces need based reports more frequently than it does in case of the private sector.

(vi) Relevance - Relevance is yet another key attribute of management information. Information is said to be relevant if it answers specifically for the recipient what, where, when, who and why? In other words, MIS should serve reports to managers which are useful and the information helps them in taking decisions. Some of the irrelevant reports may be tolerated by strategic level managers. Management control level managers, to some extent, too may not be affected adversely by irrelevant reports. But the operational level managers should get only the relevant reports as they have to take decision on very specific jobs. Therefore, they require reports about the specific jobs they are to deal with. However, what is relevant information for one recipient is not necessarily relevant for another. 
MIS is deemed as serving its purpose if it helps the management in providing relevant information. In case of PSUs the reports generated were found 'always' and 'occasionally' relevant by 44 percent and 28 percent of the respondents, while in case PSEs the similar experience was disclosed by 52 percent and 16 percent of the respondents, with the exception of 4 percent of PSE respondents holding the reports 'never' relevant, the remaining did not respond to this query.

In case of reports received, 40 percent of PSU respondents felt that reports were 'always' relevant, 20 percent said 'occasionally' and 40 percent did not reply, while in case of PSEs, for the same it was 36 percent, 16 percent and 44 percent respectively. Here again the remaining 4 percent of the PSE respondents viewed the reports received as 'never' relevant. The analysis with respect to relevance in the reports makes a slight departure from the one that has been carried out earlier. In the present analysis, the private sector has come ahead of the public sector.

(vii) Adequacy - Adequacy is vital attribute of information which underscores that a report should cover all related aspects about a particular event or situation which the report is reporting. Operational level managers will not be in position to decide the future course of action in the absence of adequate information. However, strategic level managers have outside sources of information like government reports, notification, circulars, exchange of notes with others in industry and the like. Management control level managers, too, need a high level of adequacy otherwise, they will find themselves handicapped in justifying their decisions and actions.

The reports should be adequate in contents, size and all other requisites. In case of PSUs the responses of the MCL managers for repots generated and received were the same as for relevance attribute. In this regard 36 percent of the PSE respondents opined that MIS was 'always' generating adequate reports, 24 percent said 'occasionally' 4 percent said 'never' and 36 percent did not reply, while the respective responses with respect to the reports received were 28 percent, 32 percent, nil percent and 40 percent respectively.

The public sector has again taken an edge over private sector for ensuring the adequacy by MIS for both types of reports generated and received. This can be attributed to more dependence of public sector on the prescribed formats that obviously ensure adequacy and accuracy.

(viii) Flexibility: It is another important attribute that facilitates to incorporate the changes taking place frequently in the complex environment of business organizations. In case of PSUs the flexibility in the reports generated was 'always' felt by 28 percent, 'occasionally' by 40 percent, 'never' by 4 percent respondents while remaining 28 percent preferred not to reply. While in case of PSEs, the percentage of respondents for the corresponding categories were 24, 32, 8 and 36 respectively and for the reports received PSUs were ahead of PSEs for 'always' and 'occasionally' responses.

In Both sectors MCL managers observed that flexibility was there in the reports generated in greater degree than in reports received. In both the sectors for this attribute percentage of respondents in case of 'always' category was the least recorded so far for any attribute.

(ix) Economy: The information provided by MIS should be economical as well. As management are also bound to be cost-conscious, they have to be very much particular and serious about this attribute otherwise, the very purpose of MIS may not be fulfilled.

Operational level managers have to be guided about the cost aspect in generating the reports as large number of reports are generated at this level. Similarly, the managers at the management control level are to be cost conscious to save the resources of the organization. Strategic level managers are least to bother about this aspect.

It was informed by 44 percent of the PSU respondents that the reports generated by MIS were 'always' economical, 12 percent said it was 'occasionally' and 44 percent did not reply, While in PSEs, the percentages for corresponding categories were 24,24 and 48 respectively. 
For the reports received, 28 percent of PSU respondents opined that they were 'always' economical, 16 percent said 'occasionally' and 56 percent did not reply, while of the respondents of PSEs, for the same categories of responses the percentages were 24,20 and 52 respectively.

The MIS in public sector seems more economical than in the private sector. The MCL managers have again confirmed that it is more economical for the reports generated than the reports received.

(x) Factualness: The factual information is another indicator for measuring the effectiveness of MIS. As to the reports generated in PSUs , 28 percent of the respondents were of opinion that MIS was ' always ' providing factual information, 32 percent said 'occasionally' and 40 percent did not reply. In case of PSEs, similar opinions were offered by 32 percent , 28 percent and 40 percent respondents.

For the reports received, PSUs were found ahead of PSEs with respect to 'always' and 'occasionally' responses to the factualness.

(xi) Exceptional Reporting: In present times, more and more organisations are following 'management by exception' approach. Exceptional reporting principle states that only those information which will be of a particular interest to a manager are reported. Usually, these information indicate that normal operations have gone awry, for strategic level managers only exceptional reports regarding performance of the organisation are needed. This will result in saving their precious time and to devote more time for pursuing the alternatives for the growth of the organisation. Management control level managers also require exceptional reports. But it is not true in case of operational level managers.

The principle of exceptional reporting is another important attribute that MIS should posses 16 percent of PSU respondents were sure that reports generated by MIS were 'always' based on the principle of exceptional reporting, 20 percent said 'occasionally', 20 percent felt 'never' and 44 percent did not reply, while in case of PSEs the percentages for corresponding categories were $24,20,48$ and 8 respectively.

For reports received, PSEs took an edge over PSUs in case of 'always' and 'occasionally' responses.

A peculiar trend that was noticed relates to the radically increasing number of the people who preferred not to reply to some of the attributes. The greater percentage of those respondents who did not reply in context of questions concerning factualness, flexibility, adequacy and accuracy and exceptional reporting either speaks of the ignorance of the people concerned about the intricate and complex nature of these questions or reticence on their part. concerned

It may be concluded that MIS in private sector is more effective than public sector as far as this attribute is

\section{CONCLUSION}

From the study of the presence of various attributes in reports produced by MIS in public and private sectors, it is quite obvious that the former is ahead of the latter in this respect. It is important to note that a larger percentage of respondents in both sectors opined that the attributes under reference were found more in reports generated than the reports received. The whole analysis leads to the inference that the reports generated by MIS in public sector are relatively more qualitative in terms of the presence of various attributes of information.

\section{AUTHORS INFORMATION}

Dr. P.K. Malik is well known academician. After completing his post-graduation in commerce with Gold Medal from Kurukshetra University, Kurukshetra, he selected the noble profession of teaching. He has served different institutions in various capacities. Presently, he is serving in highly reputed institution with A+ rank of a national accreditation agency NAAC and a Centre with Potential for Excellence of UGC New Delhi. So far, he has authored seven books on different educational themes, guided 25 M.Phil. students and two Ph.D. research fellows. He is 
regarded as the research icon in the region as he has completed his post-doctoral fellowship from U.G.C., New Delhi and a major research project. His number of articles has been published in various journals and is also engaged in work of reviewer of research articles. He is currently at G.N.K. (PG) College, Yamuna Nagar - 135 001, Haryana (INDIA), under Kurukshetra University, Kurukshetra, India. E-mail: pkm2003ynr@ rediffmail.com (Corresponding author)

Dr. Ranjana Malik is a lively academician and a keen researcher. She is in this profession for the last 22 years and served in various capacities. Presently, she is in the Department of Commerce in the capacity of Associate Professor. She has authored two books and was co-investigator in a major research project of U.G.C., New Delhi. She has guided number of research scholars and is an active participant in national and international educational events. She is currently at G.N.K. (PG) College, Yamuna Nagar - 135 001, Haryana (INDIA), under Kurukshetra University, Kurukshetra, India. E-mail: ranjanamalik62@gmail.com

\section{REFERENCES}

1. Acharayas, S.C. (1986). Techniques on operation research and computer based MIS. Management Accountant, 21.

2. Alter, Steven (1978). Development patterns for decision support system. MIS quarterly, 3, 33-41.

3. Banerjee, A.K. (1988). Computer aided MIS in PSUs in India. Management Accountant, 23(8), 549-551.

4. Chandrasekaran, G. and R. Ramesh (1987). Micro computer based multiple criteria decision support system for strategic planning. Information and management - International journal of information system application: system, objectives, solutions, 4.

5. Dearden, John and Mcforlen, F.Warren (1965). How to organize information system. Harvard business review.

6. Dubhasi, P.R. (1984). Management information system - an essential tool of plan implementation. Management in government, 302-305.

7. Ein-Dor, Phillip and Segev, Eli (1978). Strategic planning for management information system. Management science, 1631-41.

8. Gorry. G. Anthony and Scott Morton, Michael S. (1971). A framework for management information system. Sloan management review, 55-70.

9. Gupta, B.M. (1988). Application of management information system. Management in government, 11(23), 163-73.

10. Huber, George P. (1981). The nature of organizational decision making and the design of decision support system. MIS quarterly, 1-10.

11. Jetlie, J.L. (1971). MIS: A subjective study. Management Accountant, 6(6), 344-46.

12. Kennedy, Miles H. and Mahapatra, Sitikantha (1975). Information analysis for effective planning and control. Sloan management review, 71-33.

13. Miller, J. and Doyle, B.A. (1987). Measuring the effectiveness of computer based information system in the financial service sector. MIS quarterly, 107-124.

14. Padmanabhan, M. (1981). Management information system for the top management. Management Accountant, 16(9), 439.

15. Rao, Rajeshwar and Sarma, Subramanya (1988). MIS for finance in public sector undertakings - a case study. Management Accountant, 23(9), 631-634.

16. Silk, D.J. (1990). Information management: the Hanlay-IBM study contract. International Journal of Information Management, 10, 14-34.

17. Srinivasan, A.V. (1983). Information system for corporate growth plan: a note, ASCI journal of management, 100-107.

18. Trivedi, Prajapati (1998). Public enterprises performance and information system: a proposal. Economic and political weekly, 23(48), 140-146.

19. Vierck, Robert K. (1981). Decision support systems: an MIS manager's perspective. MIS quarterly.

20. Vithal, M.P. (1984). Computers and Management. The patriort, 14.

21. Wendler, Clifford (1966). What are the earmarks of effective total systems. Systems and procedures journal, 17 (4), 29-31. 